\title{
Degradation of a model azo dye in submerged anaerobic membrane bioreactor (SAMBR) operated with powdered activated carbon (PAC)
}

\author{
B.E.L. Baêta ${ }^{\mathrm{a}, *}$, H.J. Luna ${ }^{\mathrm{b}}$, A.L. Sanson ${ }^{\text {a }}$, S.Q. Silva ${ }^{\mathrm{c}}$, S.F. Aquino ${ }^{\mathrm{d}}$ \\ ${ }^{a}$ Post-Graduate Programme in Environmental Engineering, Federal University of Ouro Preto, Ouro Preto 35400-000, Brazil \\ ${ }^{\mathrm{b}}$ Post-Graduate Programme in Environmental Engineering, University of the Andes, Bogotá, Colombia \\ ${ }^{\mathrm{c}}$ Biological Sciences Department, Federal University of Ouro Preto, Ouro Preto, Brazil \\ ${ }^{\mathrm{d}}$ Chemistry Department, Federal University of Ouro Preto, Ouro Preto, Brazil
}

\section{A R T I C L E I N F O}

\section{Article history:}

Received 25 October 2012

Received in revised form

26 February 2013

Accepted 17 May 2013

Available online 26 June 2013

\section{Keywords:}

Submerged anaerobic membrane bioreactor (SAMBR)

Azo dye

Powdered activated carbon (PAC)

Volatile fatty acids (VFA)

\begin{abstract}
A B S T R A C T
This work investigated the anaerobic degradation of the model azo dye Remazol Yellow Gold RNL in an upflow anaerobic sludge blanket reactor (UASB) and two submerged anaerobic membrane (SAMBR) bioreactors, one of which (SAMBR-1) was operated with powdered activated carbon (PAC) in its interior. The reactors were operated at $35{ }^{\circ} \mathrm{C}$ with a hydraulic retention time of $24 \mathrm{~h}$ in three operational phases, aimed to assess the effect of external sources of carbon (glucose) or redox mediator (yeast extract) on the removal or color and organic matter. The results showed that removal efficiencies of COD (73-94\%) and color (90-94\%) were higher for SAMBR-1 when compared to SAMBR-2 (operated without PAC) and UASB reactors. In addition, the presence of PAC in SAMBR-1 increased reactor stability, thereby leading to a lower accumulation of volatile fatty acids (VFA). The microfiltration membrane was responsible for an additional removal of $\sim 50 \%$ of soluble residual COD in the form of VFA, thus improving permeate quality. On its turn, PAC exhibited the ability to adsorb byproducts (aromatic amines) of azo dye degradation as well as to act as source of immobilized redox mediator (quinone groups on its surface), thereby enhancing color removal.
\end{abstract}

(c) 2013 Elsevier Ltd. All rights reserved.

\section{Introduction}

In the last years, the textile industry has grown economically at national and international level leading to a high production of wastewater which is mainly produced in the units of desizing, scouring, bleaching, mercerizing, dyeing and printing (Kumar et al., 2008). In general textile wastewater has a great amount of organic compounds such as surfactants, softeners, fixers and dyes. These compounds contribute to Chemical Oxygen Demand (COD) or cause considerable color to the effluent in the case of dyes. Textile dyes lead to a disagreeable aesthetic aspect, and compromise the photosynthesis of algae, which reduces the amount of Dissolved Oxygen (DO) and might lead to mortality of aquatic species (Weisburger, 2002). In addition, textile dyes damages the environment and poses a threat to the human health, since some of them or their byproducts are carcinogenic or mutagenic (Kalyuzhnyi and Sklyar, 2000). It is estimated that there are more than 3000 types of dyes, and that the azo type, characterized by the

\footnotetext{
* Corresponding author. Tel.: +55 (0)31 35591837.

E-mail address: bruno.baeta@ambiental.ufop.br (B.E.L. Baêta).
}

presence of one or more $-\mathrm{N}=\mathrm{N}-$ bond, represents $\sim 70 \%$ of the commercialized dyes (Hunger et al., 2004).

Textile effluents can be treated by a variety of processes, which includes biological and physical-chemical schemes. In Brazil most textile industries employ, for treatment of their wastewater, the well-known biological process of activated sludge. Such process is normally efficient in removing the organic load from wastewater, but is not so effective in decolorizing it. The use of activated carbon or coagulants might be used as a complement, which normally generates a high amount of sludge that needs to be properly handled (Santos et al., 2009). According to Van Der Zee and Villaverde (2005) currently there is no single technology capable of efficiently and economically removing color from textile effluents, which keeps open research opportunities in this field.

An important wastewater treatment technology that has been researched for azo dyes removal is the anaerobic digestion (Georgiou and Aivasidis, 2006). Some electrophilic contaminants, such as the azo dyes, can be used as final electron acceptor in anaerobic environments, thereby leading to the reduction of dye chromophore system and color removal. Indeed, different research groups have found that anaerobic biotechnology is more efficient in azo dye degradation when compared with its aerobic counterpart, 
and have reported removal efficiencies varying from $60 \%$ to $80 \%$ for COD and from $40 \%$ to $95 \%$ for color (Baêta et al., 2012a; Dos Santos et al., 2006; Méndez-Paz et al., 2005).

One strategy to increase the efficiency of color removal in anaerobic systems is the use of redox mediators (Dos Santos et al., 2005), since such compounds would enhance the kinetics of azo dye degradation by acting as electron carriers. Several authors have shown that compounds such as riboflavin (vitamin B2) and quinone-like compounds can act as redox mediators Cervantes et al., 2001; Field and Brady, 2003; Rau et al., 2002). However, one disadvantage of anaerobic treatment of azo dyes is the formation of toxic byproducts such as aromatic amines, which can lead to volatile fatty acids (VFA) accumulation and process failure in terms of COD removal, de-granulation and biomass loss.

In order to minimize biomass loss triggered by the presence of toxic compounds some alternatives like the use of the membrane and powdered activated carbon (PAC) are suggested in the literature (Baêta et al., 2012a, b). The use of membranes immersed in anaerobic reactors increases the cell retention time and produces a better quality effluent, which can be reused as process water (Hu and Stuckey, 2006). In its turn, the addition of PAC can control toxicity, improve the granulation process and help to control membrane fouling due to the adsorption of proteins, biopolymers and soluble microbial products (Akram and Stuckey, 2008; Aquino et al., 2006).

Given the obvious advantages offered by the anaerobic biotechnology (low installation and operation costs) and by membrane process when treating distinct types of wastewater (improves effluent quality, increases sludge age), the main objective of this study was to evaluate the performance of submerged anaerobic membrane bioreactors (SAMBR) when compared to upflow anaerobic sludge blanket reactor (UASB) in the removal of an azo dye (Remazol Yellow Gold RNL) largely used in our region. In addition, the influence of PAC addition inside the SAMBR and the effect of yeast extract (source of the redox mediator riboflavin) on color removal were also investigated.

\section{Material and methods}

\subsection{Apparatus and operational conditions}

Two SAMBR (anaerobic reactors with microfiltration module placed inside of their settler compartment, i.e. side arm at the reactor's top right as seen in Fig. 1) were built using polyvinyl chloride (PVC) pipes and fittings, and each reactor had a working volume of
$3.25 \mathrm{~L}$. The microfiltration membranes $\left(0.8 \mathrm{~m}^{2}\right.$ of hollow fibers, with pore sizes of $0.4 \mu \mathrm{m}$ ) were made of Polyimide and the modules were manufactured by PAM membranes (PAM - Membranas Seletivas ${ }^{\circledR}$ ). A third anaerobic system (UASB reactor) was built as control and had a working volume of $3.25 \mathrm{~L} \mathrm{Fig.} 1$ shows the scheme of the SAMBR (A) and UASB (B) reactors used.

SAMBR-1 was operated with $4.0 \mathrm{~g} \mathrm{~L}^{-1}$ of PAC (Synth ${ }^{\circledR}$ ) in its interior, whereas the SAMBR-2 and UASB were operated without such adsorbent. The choice for this concentration of PAC is based in others works reported in the literature (Akram and Stuckey, 2008; van der zee et al., 2003). It is noteworthy that PAC was added only once, at the beginning of SAMBR-1 operation. All three reactors were operated at $35{ }^{\circ} \mathrm{C}$ using a hydraulic retention time (HRT) of $24 \mathrm{~h}$, which was the HRT employed by other authors such as Dos Santos et al. (2005) to treat the same type of wastewater. During operation the $\mathrm{pH}$ was kept in the $6.5-7.5$ range by adding $\mathrm{Na}_{2} \mathrm{CO}_{3}$ $0.1 \mathrm{M}$ or $\mathrm{HCl} 0.01 \mathrm{M}$ directly into the reactors, despite the fact that the yeast extract (Himedia ${ }^{\circledR}$ ) solution contained sodium bicarbonate as a buffer and micro and macronutrients. The composition of nutrient solution was chosen to maintain the minimum COD: $\mathrm{N}: \mathrm{P}$ proportion of 350:5:1 (Mesquita et al., 2012).

The reactors were incubated with $0.8 \mathrm{~L}$ of anaerobic sludge $\left(10 \mathrm{~g} \mathrm{~L}^{-1}\right)$ from a demo scale UASB reactor fed with raw sewage in operation at the Center for Research and Training on Saniation (CePTS) UFMG/COPASA, located at the Arrudas WWTP, which receives the major part of the domestic sewage of the urban area of Belo Horizonte city (Minas Gerais state, Brazil).

All reactors (SAMBR-1, SAMBR-2 and UASB) were operated during three phases, where each phase lasted $\sim 42$ days, counted only after reactor stabilization. The stabilization time was determined when the variation of COD removal efficiency was lower than $5 \%$. The conditions of each phase as well as the objectives are shown in Table 1.

\subsection{Analytical procedures}

During reactor operation, samples of influent and effluent were collected five times a week for analysis of chemical oxygen demand (COD), color, $\mathrm{pH}$ and turbidity. In addition, samples of anaerobic effluent and from inside of the reactors (SAMBR-1, SAMBR-2 and UASB) were collected once a week for analysis of volatile suspended solids (VSS) and volatile fatty acids (VFA). The analysis of COD, $\mathrm{pH}$, turbidity and VSS followed the procedures detailed in the Standard Methods for the Examination of Water and Wastewater (Clescerl et al., 2005).

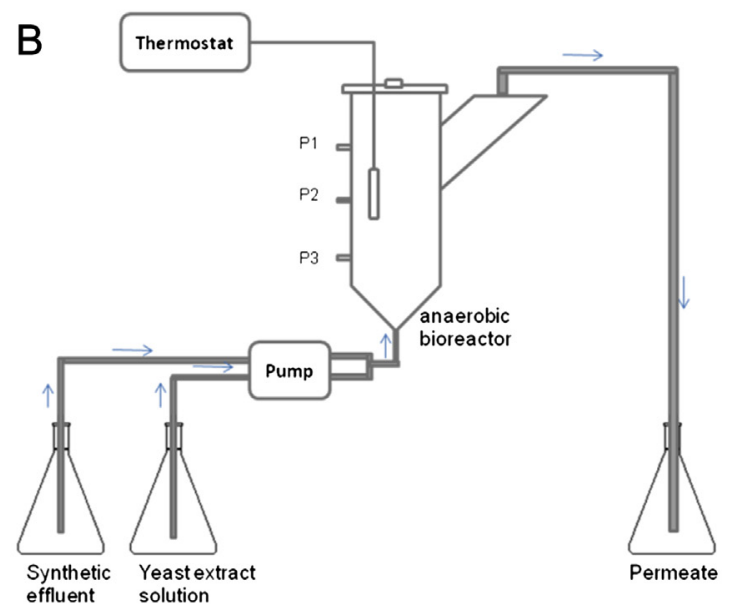

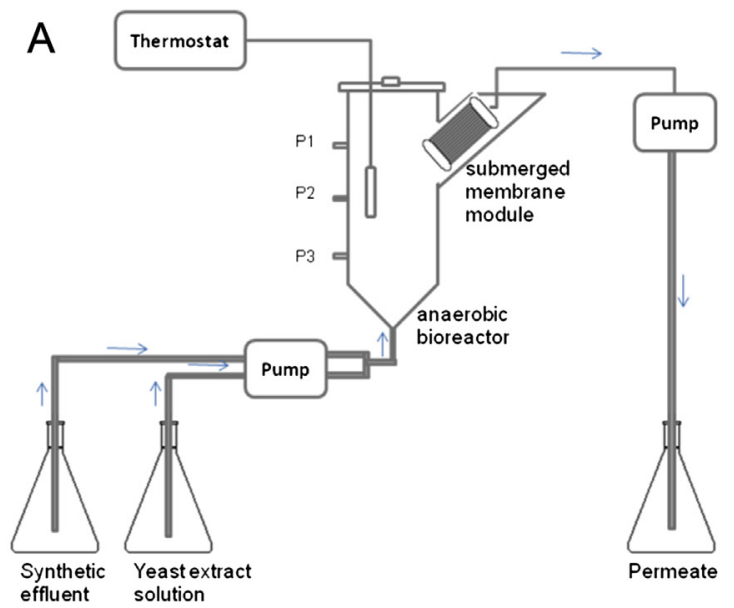

Fig. 1. Scheme of the bench SAMBR (A) and UASB (B) reactors used. 
Table 1

Operational phases of the reactors SAMBR-1, SAMBR-2 and UASB.

\begin{tabular}{|c|c|c|c|c|c|c|c|}
\hline Phases & Dye $\left(\mathrm{mg} \mathrm{L}^{-1}\right)$ & $\begin{array}{l}\text { Nutrient } \\
\text { Solution }^{\mathrm{a}}\end{array}$ & $\begin{array}{l}\text { Yeast } \\
\text { Extract }^{\mathrm{b}}\left(\mathrm{mg} \mathrm{L}^{-1}\right)\end{array}$ & $\begin{array}{l}\text { Glucose }^{c} \\
\left(\mathrm{mg} \mathrm{L}^{-1}\right)\end{array}$ & $\begin{array}{l}\text { Organic Load } \\
\left(\mathrm{kg} \mathrm{m}^{-3} \mathrm{~d}^{-1}\right)\end{array}$ & $\begin{array}{l}\text { Operation } \\
\text { time }(\mathrm{d})\end{array}$ & Objective \\
\hline 1 & No & Yes & No & Yes (500) & 0.53 & 42 & Biomass Adaptation \\
\hline 2 & Remazol Yellow Gold RNL (50) & Yes & No & Yes (500) & 0.59 & 42 & $\begin{array}{l}\text { Assessment of glucose as } \\
\text { carbon source }\end{array}$ \\
\hline 3 & Remazol Yellow Gold RNL (50) & Yes & Yes (500) & No & 0.59 & 42 & $\begin{array}{l}\text { Assessment of yeast extract } \\
\text { as source of redox mediator }\end{array}$ \\
\hline
\end{tabular}

\footnotetext{
a As described in Mesquita et al. (2010).

b Contained $50 \mu \mathrm{g} / \mathrm{g}$ of redox mediator riboflavin.

c Used as a source of carbon.
}

COD analysis was employed with the supernatant obtained after centrifuging the sample for $15 \mathrm{~min}$ at $5000 \mathrm{rpm}$ (Fanem Excelsa 11 centrifuges, model $206 \mathrm{BL}$ ), hence the results of COD refer to the soluble fraction. Color analysis was measured using a spectrophotometer (HP $8453 \mathrm{UV}-$ Visible system) in the wavelength of highest absorbance $(\lambda=410 \mathrm{~nm})$ of Remazol Yellow Gold, RNL, the model azo dye which was generously provided by a local textile industry and used in this study without purification.

VFA was analyzed by high performance liquid chromatography (HPLC) using an ion exchange column (Aminex HPX-87H, BioRad) which was kept at $55{ }^{\circ} \mathrm{C}$ under isocratic mode $\left(0.6 \mathrm{ml} \mathrm{min}^{-1}\right.$ of $\mathrm{H}_{2} \mathrm{SO}_{4} 0.01 \mathrm{M}$ ). For this, $10 \mu \mathrm{L}$ of the centrifuged samples was injected in the Shimadzu HPLC so that the separated VFA could be detected at $210 \mathrm{~nm}$ in a diode array detector (DAD). The VFA method was properly validated as detailed elsewhere (Mesquita et al., 2012).

VFA concentration was then used to estimate the fraction of COD due to such intermediate compounds, according to Equation (1).

$$
\begin{aligned}
\mathrm{COD}(\mathrm{VFA})= & 0.35 \times[\text { formate }]+1.07 \times[\text { acetate }]+1.51 \\
& \times[\text { propionate }]+1.82 \times[\text { butyrate }+ \text { isobutyrate }] \\
& +2.04[\text { valerate }+ \text { isovalerate }]
\end{aligned}
$$

The identification of aromatic amines generated in the anaerobic degradation of Remazol Yellow Gold RNL was carried out using the same methodology described before for VFA analysis, however their detection was at $191 \mathrm{~nm}$, since according to Pinheiro et al. (2004) at this wavelength the aromatic amines (e.g. sulfanilic acid) generated as byproducts of sulfonated azo dye degradation have higher absorbance.

The identification of quinone groups on the surface of PAC was accomplished by Fourier Transformed Infrared (FTIR) spectroscopy in a Shimadzu equipment (model IR Affinity) using a deuterated detector (triglycine sulfate doped with L-Alanine, DLATGS) in the frequency range of $4000-400 \mathrm{~cm}^{-1}$ and employing a diffuse reflectance accessory.

\subsection{Adsorptions tests}

To estimate VFA adsorption by PAC, samples from inside the SAMBR-2 were used in batch adsorption tests. For this, $100 \mathrm{~mL}$ of centrifuged samples from inside SAMBR-2 were transferred to five erlenmeyers kept at $35^{\circ} \mathrm{C}$ and $200 \mathrm{rpm}$ for $24 \mathrm{~h}$ in an orbital shaker (model SL 120250, Solab ${ }^{\circledR}$ ), which received distinct mass of PAC (from 1 to $8 \mathrm{~g} / \mathrm{L}$ ). The concentration of VFA in the samples was previously evaluated and a known amount of VFA was spiked to the SAMBR-2 samples to raise the concentration of acetic, propionic and butyric acid to $200 \mathrm{mg} \mathrm{L}^{-1}$.

After the equilibrium was reached $(12 \mathrm{~h})$ the erlenmeyer samples were centrifuged and analyzed for VFA. Adsorption data was then used with the isotherm models of Langmuir, Freundlich and Temkin, as described elsewhere (Teixeira et al., 2012).
To measure the azo dye adsorption by PAC $200 \mathrm{~mL}$ of azo dye solutions $(50,40,30,10$ and $1 \mathrm{mg} / \mathrm{L})$ were kept under stir (300 rpm) for $2 \mathrm{~h}$ with a fixed amount of PAC ( $4 \mathrm{~g} / \mathrm{L})$. After this contact time the solutions were centrifuged and the amount of azo dye adsorbed in each flask was evaluated by measuring the solutions absorbance at $410 \mathrm{~nm}$. The adsorption data was analyzed according to the isotherm models of Langmuir, Freundlich and Temkin, as described elsewhere (Teixeira et al., 2012).

\subsection{Specific microbial growth rate determination}

The specific microbial growth rate $(\mu)$ was estimated taking into account the volatile suspended solid (VSS) variation during the operational time in each phase. The results were obtained according to Equation (2), where ( $d X)$ is the VSS mass change, $\left(X_{0}\right)$ the initial VSS mass used to inoculate the reactors and $(\mathrm{d} t)$ the run time employed in each phase. It is noteworthy that to calculate the mass of VSS in SAMBR-1, a previous study was carried out to evaluate the contribution of PAC to the volatile solids, as detailed in (Baêta et al., 2012a).

$\mu=\mathrm{d} X / X_{0} \cdot \mathrm{d} t$

\subsection{Statistical analysis}

In order to verify whether the differences observed between the SAMBR and UASB were significant, statistical tests were employed by means of the software Statistica ${ }^{\circledR}$. The Shapiro-Wilk test was used to confirm that the results did not follow a normal distribution, and then non-parametric tests (Kruskal-Wallis ANOVA, Student-Newman and Mann-Whitney) were applied. A $p$-value lower than 0.05 was adopted for rejecting the null hypothesis $\left(H_{0}\right)$.

\section{Results and discussion}

Fig. 2 (A) shows the COD efficiency removal for all reactors during the three operational phases. It can be seen that the membrane reactors SAMBR-1 and SAMBR-2 led to higher percentages of COD removal when compared to UASB reactor. This clearly shows the membrane positively contributed for organic matter removal, possibly by retaining colloidal organic compounds such as protein and polysaccharides generated from biomass decay (soluble microbial products) as shown before by Aquino et al. (2006). Furthermore, the reactor SAMBR-1 had a better performance in removing organic matter than SAMBR-2, and this is due to the fact that SAMBR-1 was operated with a concentration of $4 \mathrm{~g} / \mathrm{L}$ of PAC in its interior. This shows that PAC positively influenced the removal of organic matter in the anaerobic system, probably by adsorbing toxic intermediate compounds, as it will be discussed later. In addition, Fig. 2(A) shows that when the reactors SAMBR-1 and SAMBR-2 were fed with yeast extract (phase 3 ) there was an increase in the COD removal efficiency, which was probably due to 

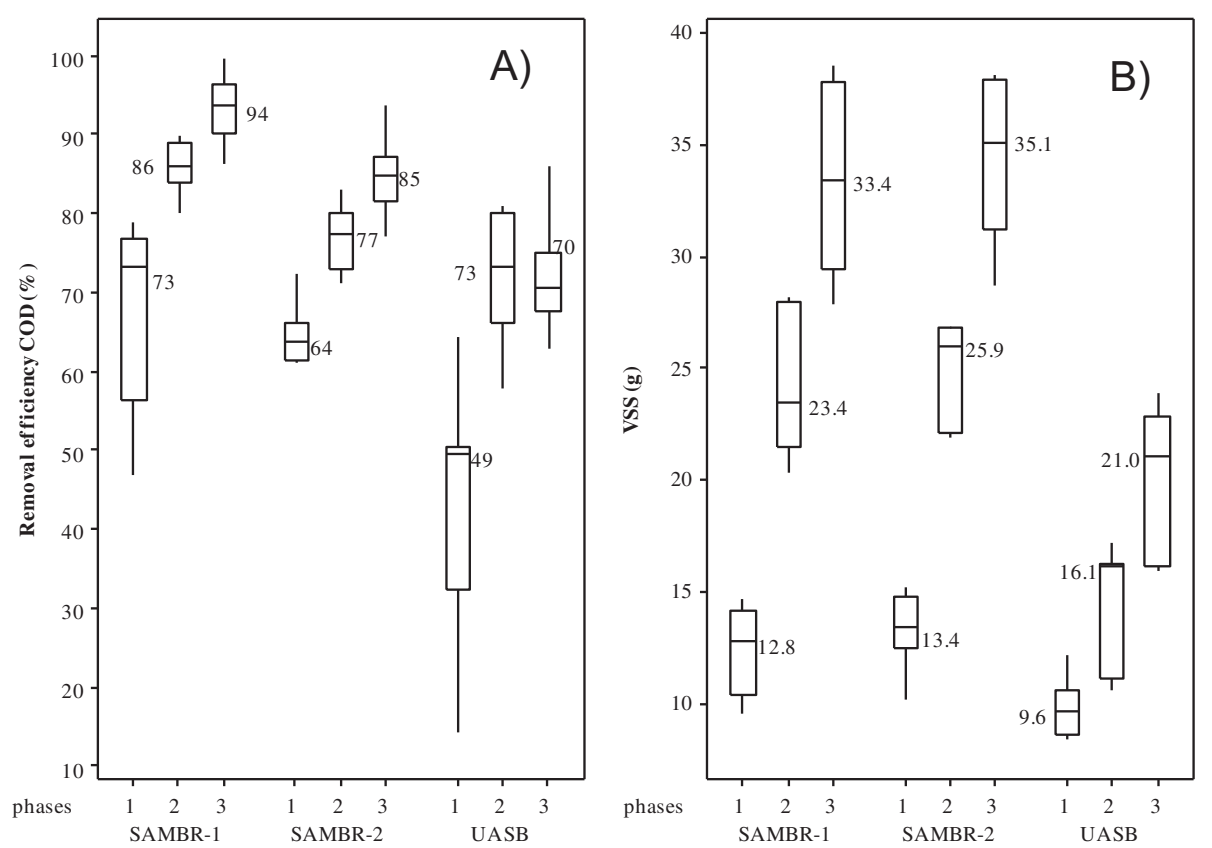

Fig. 2. Soluble COD efficiency removal (A) and amount of VSS (B) inside reactors SAMBR-1, SAMBR-2 and UASB throughout the operational phases.

the presence of yeast extract, source of the redox mediator riboflavin.

SAMBR-1 exhibited higher median COD removal efficiencies ( $>70 \%$ ) in all operational phases, which were statistically different (p-valued $<0.05$ ) from those exhibited by SAMBR-2 and UASB. During Phase 3 the median removal efficiency increased to $94 \%$ in SAMBR-1, and this is at even with the results obtained by Akram and Stuckey (2008) who observed higher organic matter removal (94\% in average) when a SAMBR containing PAC $(1.7 \mathrm{~g} / \mathrm{L})$ was operated with sucrose as carbon source under an HRT of $20 \mathrm{~h}$.

A hypothesis to explain the high values of organic matter removal obtained in all operational phases of the reactors SAMBR-1 and SAMBR-2, when compared to the UASB reactor, is that the microfiltration enhanced the effluent quality by retaining colloidal material and active biomass, which could not be accomplished in the UASB despite the lower upflow velocities employed. It is well known that microfiltration membranes can promoted an increase in the cell retention time (CRT), thus avoiding sludge washout (Dereli et al., 2012), especially in systems operated under stressful conditions. According to Liao et al. (2006) there is a direct relationship between the CRT, biomass accumulation and COD removal efficiency, which is confirmed by Fig. 2B which shows there was a higher amount of biomass inside the SAMBR in all operational phases.

Another behavior observed in the SAMBR was the low COD concentration (CODVFA and CODnot VFA) in the effluents when compared to the anaerobic supernatant (inside reactors). Fig. 3 shows that when the effluent passed through the membrane, the CODVFA concentration decreased by $50 \%$, which was not observed in the UASB reactor. Considering that it is improbable that a microfiltration membrane can reject low molecular weight compounds such as acetate $(59 \mathrm{~g} / \mathrm{mol})$, propionate $(73 \mathrm{~g} / \mathrm{mol})$ and butyrate $(85 \mathrm{~g} / \mathrm{mol})$; a hypothesis for explaining the VFA reduction is the formation of a biofilm on the membrane surface. Other authors such as Martinez-Sosa et al. (2012) also found significant differences between the VFA concentration from inside SAMBR and the effluent and suggested that a biologically active part of the cake layer contributed to further degrade a part of the incoming organic load. In addition to that it is also possible that the negatively charged VFA are rejected from the membrane by electrostatic repulsion. Unfortunately we do not have zeta potential or $\mathrm{PCZ}(\mathrm{pH}$ of charge zero) of the membrane to confirm this hypothesis.

Fig. 3 also shows that CODVA inside SAMBR- 1 was significantly lower than the other two reactors during all operational phases. This behavior is probably related to the high rate of VFA degradation inside SAMBR-1, motivated by better biomass acclimation and accumulation, resulting from PAC capacity to adsorb toxic substances (e.g. aromatic amines and azo dyes) that may hamper the growth of anaerobic microorganisms and the intermediate VFA (as it will be discussed later).

Fig. 4 shows that propionate was the main VFA accumulated in all reactors, mainly in SAMBR-2 and UASB. It is well known that VFA accumulation in anaerobic systems occurs due to microbial growth imbalance caused by stressful conditions such as nutrient deficiency and toxicity, as well as due to kinetic and thermodynamic constraints (Aquino and Chernicharo, 2005). Since all reactors were fed with nutrient solution and at the same environmental conditions, the lower accumulation of propionate in SAMBR-1 is mainly attributed to the adsorption of aromatic amines by PAC, since the accumulation of such azo dye degradation byproducts was low in SAMBR-1 despite the high color removal efficiencies observed, as it will be shown later.

In addition, SAMBR-1 performance might have been enhanced by PAC due to the adsorption of intermediate VFA, thus avoiding thermodynamic inhibition of some conversion routes (e.g. propionate into acetate) and keeping an adequate balance between acid producers (e.g. acidogenesis) and consumers (e.g. acetogenesis and methanogenesis). To confirm this, adsorption studies of VFA onto PAC were carried out, as shown in Table 2 . It is noteworthy that the adsorption data was tested with Freundlich, Langmuir and Temkin isotherm models, but Table 2 shows only Langmuir model parameters since it yielded the best fitting.

Table 2 shows that PAC exhibited a relatively high adsorption capacity for acetate and butyrate, and based on the values of $Q_{\max }$ it was possible to estimate that the PAC added inside the reactor at the beginning of SAMBR-1 operation would be able to retain 

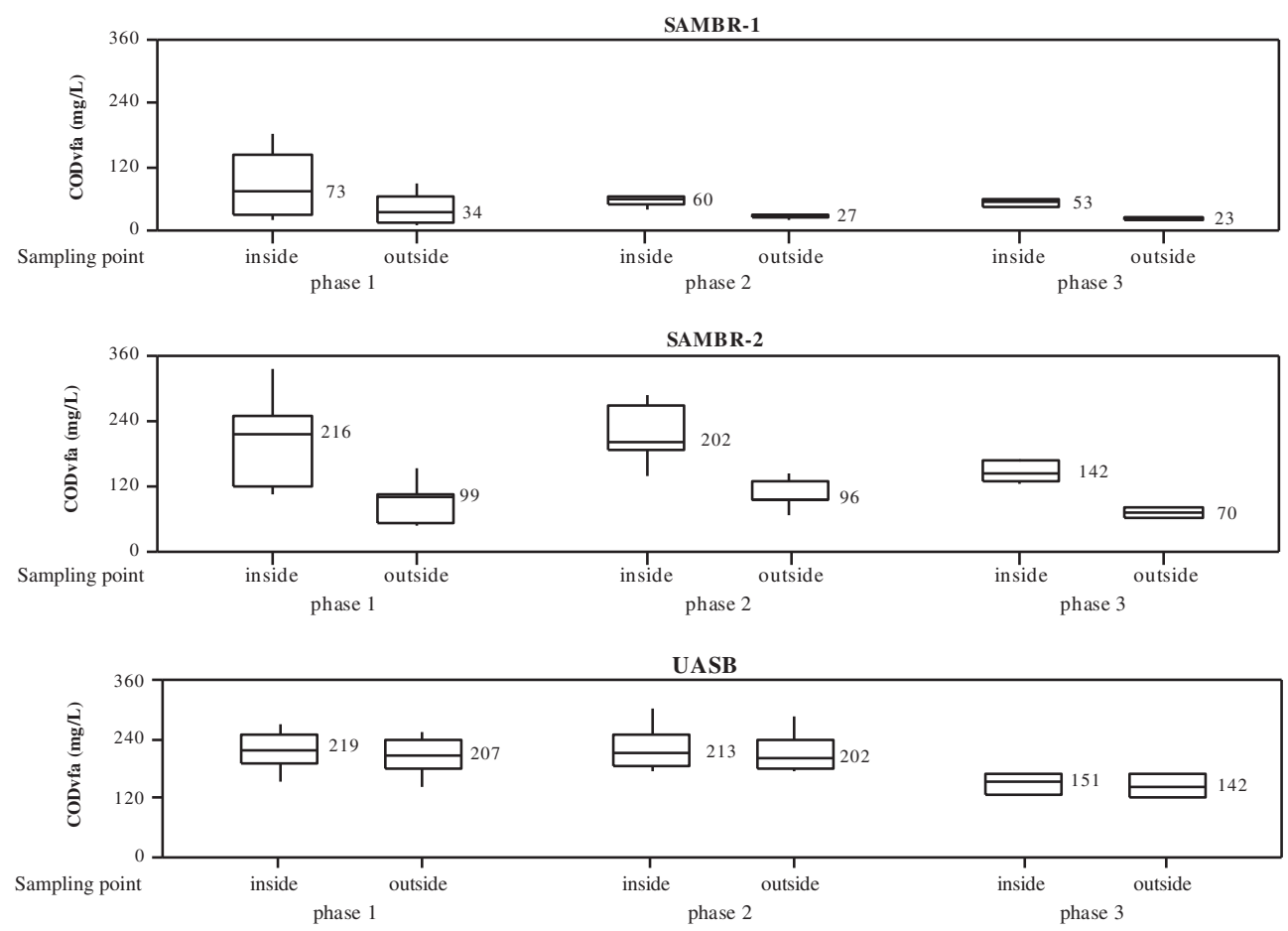

Fig. 3. Evaluation of $C O D_{V F A}$ in samples from inside and effluent of reactors SAMBR-1(with PAC), SAMBR-2(without PAC) and UASB.

$81.2 \mathrm{mg}$ of acetate on its surface. The acetate concentration differences observed between SAMBR 1 and 2 varied from $14 \mathrm{mg}$ (phase 3) to $46 \mathrm{mg}$ (phase 1), corroborating the hypothesis that PAC might have played an important role in keeping a low acetate concentration into the bulk solution. A lower acetate concentration would favor the acetogenic reactions, thereby reducing the accumulation of propionate and butyrate in the anaerobic supernatant and enhancing acetoclastic methanogenesis. This would, in its turn, lead to a higher COD removal from the liquid phase and better reactor stability, and Figs. 3 and 4 show this was the case for SAMBR-1.

Specific microbial growth rate $(\mu)$ was calculated (Fig. 5) and the results indicate that indeed there was a higher net growth in SAMBR- 1 when compared to SAMBR-2 and UASB. The mass of VSS
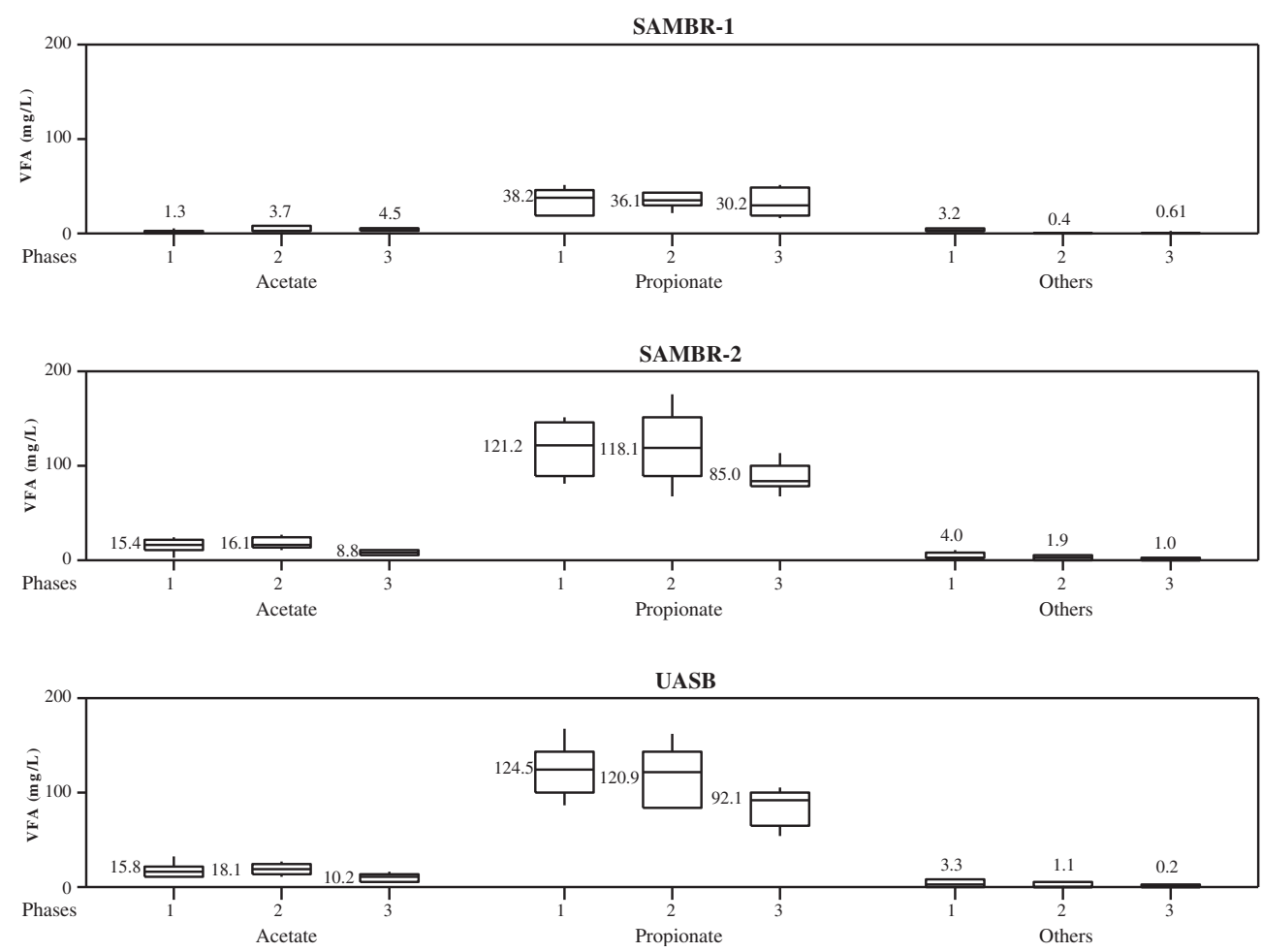

Fig. 4. Concentration of main VFA accumulated inside the reactors SAMBR-1 (with PAC), SAMBR-2(without PAC) e UASB. 
Table 2

Langmuir isotherm parameters for VFA and azo dye adsorption onto PAC.

\begin{tabular}{lllll}
\hline VFA & $Q_{\max }(\mathrm{mg} / \mathrm{g})$ & $K_{\mathrm{L}}(\mathrm{L} / \mathrm{mg})$ & $R_{\mathrm{L}}$ & $R^{2}$ \\
\hline Acetate & 5.80 & 0.0050 & 0.4999 & 0.9511 \\
Propionate & 0.096 & 4.05 & 0.0123 & 0.7706 \\
Butyrate & 5.19 & 0.0059 & 0.4567 & 0.8731 \\
Remazol Yellow Gold RNL & 9.469 & 0.2231 & 0.0823 & 0.9650 \\
\hline
\end{tabular}

in SAMBR-1 increased $11.0 \mathrm{~g}$ from phase 1 to $2 ; 13.0 \mathrm{~g}$ from phase 2 to 3 and $15.0 \mathrm{~g}$ during the third phase, whereas the VSS increase for SAMBR-2 in the same phases were respectively $8.0 \mathrm{~g}, 9.0 \mathrm{~g}$ and $8.0 \mathrm{~g}$. For the UASB the VSS increase was roughly half of that observed in SAMBR-1, i.e. $6.0 \mathrm{~g}, 8.0 \mathrm{~g}$ and $7.0 \mathrm{~g}$ respectively. This confirms the hypothesis that addition of PAC into SAMBR-1 adsorbed intermediate VFA and toxic byproducts, thereby providing a more adequate environment for microbial growth which led to higher stability when compared with the other reactors (SAMBR-2 and UASB). The fact that SAMBR-2 (without PAC) exhibited higher $\mu$ values than UASB can be attributed to higher biomass retention (higher CRT) as well as to higher degradation of colloidal material which would be retained by the membrane and serve as substrate by the anaerobic microorganisms.

According to the results presented before, the aromatic amines generated from azo dye degradation were responsible for increasing anaerobic toxicity, mainly in phase 3 and in SAMBR-2 and UASB reactors. In order to evaluate the influence of PAC in the reduction of aromatic amines concentration, chromatographic analyses were carried out as shown in Fig. 6 .

A chromatographic signal in the retention time of 8.7 min was detected in the samples collected from inside the reactors SAMBR-1 (F), SAMBR-2 (I) and UASB (L) during phase 3 (Fig. 6). The same signal, although less intense, was also detected in the samples collected from these reactors during phase 2 (SAMBR-1 (E), SAMBR$2(\mathrm{H})$ and UASB $(\mathrm{K}))$, where it was observed a lower azo dye degradation when compared to phase 3 . This signal intensity (peak at $8.7 \mathrm{~min}$ ) difference is associated with the presence of extract yeast (source of the redox mediator riboflavin) in phase 3 , which enhanced the kinetics of azo dye degradation and increased the production of aromatic amines. Since this chromatographic signal (8.7 min) was not detected in the samples from any reactor during phase 1 , it is possible to ascertain that the compounds that caused such a peak are not Soluble Microbial Products (SMP) accumulated in the reactor. In addition, such peak was not observed in the chromatograms of the azo dye (A), VFA (B) or inlet feed solution (C).

Another argument to strengthen the hypothesis that the chromatographic signal observed at $8.7 \mathrm{~min}(191 \mathrm{~nm})$ is an aromatic

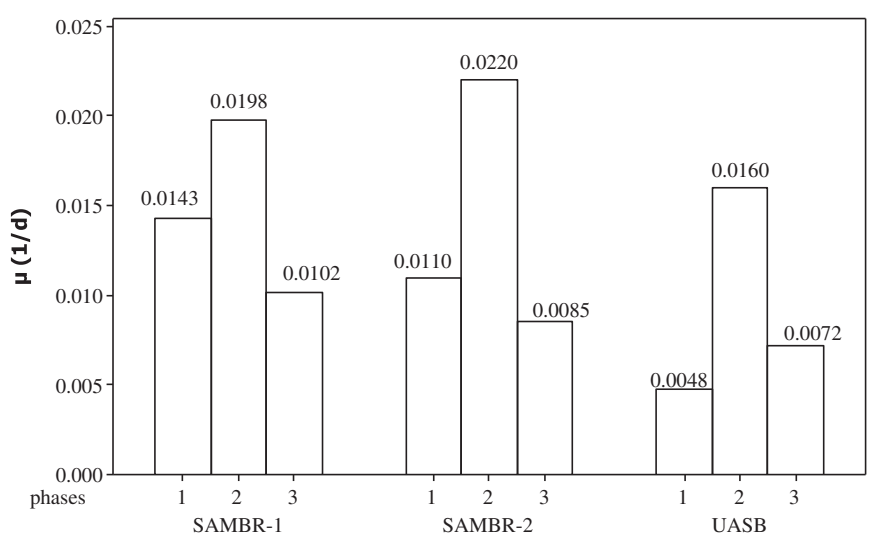

Fig. 5. Specific microbial growth rate $(\mu)$ calculated for SAMBR-1 (with PAC), SAMBR-2 (without PAC) and UASB during all operational phases. amine relates to the comparison of pKa values of VFA and sulfanilic acid (a typical amine formed from sulfonated azo dye degradation) and their respective chromatographic retention times (RT) experimentally measured. As presented in Fig. 7, the aromatic amines that result from the degradation of Remazol Yellow Gold RNL have a structure similar to that of sulfanilic acid, and thereby should have pKa values close to 3.2 (Agbaba et al., 1996). When using ion exchange chromatography the separation of analytes occurs in accordance with the speed at which each substance exchange protons $\left(\mathrm{H}^{+}\right)$with the sulfonated polymer of the column. This process happens in an acid mobile phase, where the analytes are in the protonated form. Therefore, substances with lower pKa values (more acidic) can exchange $\mathrm{H}^{+}$with the column more rapidly when compared to molecules with higher pKa values (less acidic). Since formic acid ( $\mathrm{pKa}=3.75$ ) comes from the column at $13,38 \mathrm{~min}$, it is possible to conclude that the compound eluted at 8.7 min must have a lower pKa value, and this is the case of the sulfanilic acid like aromatic amines.

Another behavior observed in Fig. 6 was the capacity of PAC in adsorbing the byproducts generated during anaerobic degradation of Remazol Yellow Gold RNL since the intensity of the chromatographic signal at 8.7 min was lower in the SAMBR-1 during the phases 2 and 3 when compared to SAMBR-2 and UASB. If one considers the efficiency of azo dye degradation during the operational phases 2 and 3 (Fig. 8), it would be expected a higher accumulation of aromatic amines inside SAMBR-1 following the higher color removal efficiencies observed in such system. However, this was not the case, confirming the hypothesis discussed before that PAC retained aromatic amines at its surface and enhanced microbial activity inside SAMBR-1, probably because it contains basic organic groups (e.g. cromene, pyrones) or rich electronic surfaces (e.g graphenic layers) that act as Lewis bases that can electrostatically interact with acidic compounds such as the sulfonated aromatic amines.

Fig. 8 shows that the membrane did not have a direct influence on azo dye removal, since there were no statistical differences ( $p$ value $>0.05$ ) in the efficiency of decolorization when the reactors SAMBR-2 and UASB are compared during phases 2 and 3. The removal of azo dye in the system was mostly influenced by the presence PAC in the reactor SAMBR- 1 and also by the presence of yeast extract in both membrane reactors during phase 3 . Indeed, the best behavior in relation to color removal was observed in SAMBR-1 during phase 3, when the decolorization reached a median efficiency of $94.3 \%$.

The positive role of yeast extract can be observed when comparing color removal efficiencies during phases 2 and 3, since an increase in azo dye removal was observed for all the reactors when the redox mediator riboflavin was added in the feed solution. This confirms other studies carried out in our labs which showed the potential of yeast extract in enhancing the kinetics of azo dye degradation in anaerobic systems (Baêta et al., 2012b; Correa et al., 2009). For instance, Baêta et al. (2012b) demonstrated that the presence of $500 \mathrm{mg} / \mathrm{L}$ of yeast extract was also able to increase by about 30\% the azo dye removal efficiency in an anaerobic UASB treating a synthetic wastewater containing Drimaren blue HFRL $(50 \mathrm{mg} / \mathrm{L})$ and operated at ambient temperature $\left(25^{\circ} \mathrm{C}\right)$ and with an HRT of $24 \mathrm{~h}$.

The beneficial role of PAC on color removal can be clearly seen comparing the efficiencies obtained during phase 2, when SAMBR1 performed $\sim 15 \%$ better than SAMBR-2 regarding effluent decolorization. Table 2 shows that PAC exhibited a relatively high adsorption capacity for Remazol Yellow Gold RNL, and based on the $Q_{\max }$ value it is possible to estimate that the PAC added inside the SAMBR-1at the beginning of its operation would be able to retain $123.5 \mathrm{mg}$ of Remazol Yellow Gold RNL if adsorption was the sole 


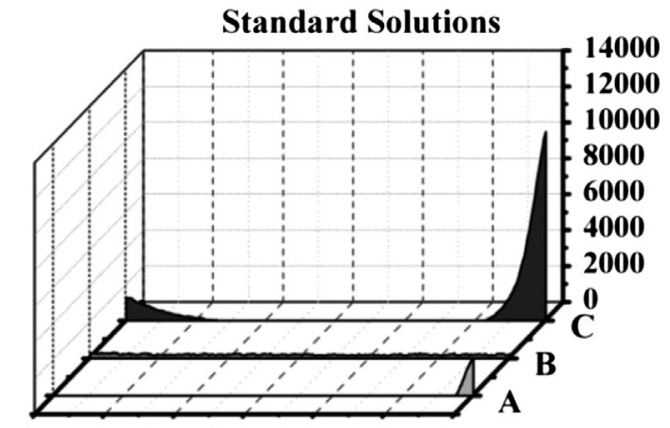

$\begin{array}{llllllll}7.0 & 7.5 & 8.0 & 8.5 & 9.0 & 9.5 & 10.0\end{array}$ SAMBR 2

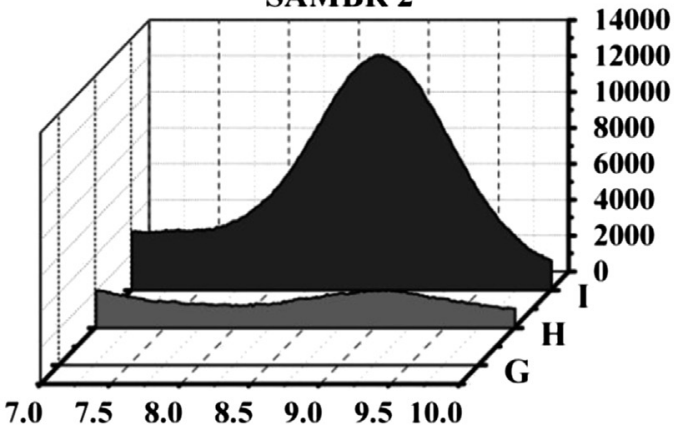

SAMBR 1

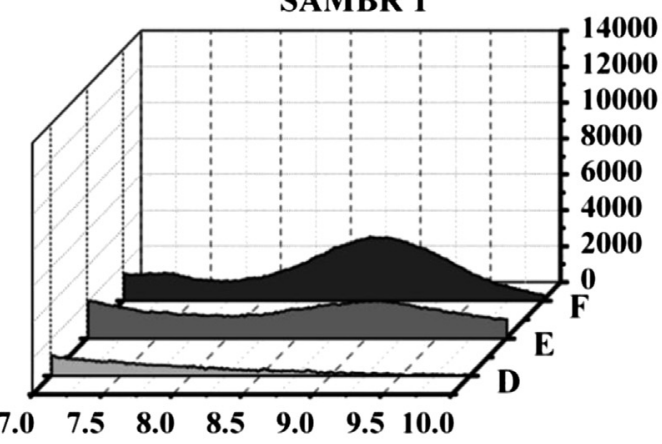

$\begin{array}{llllllll}7.0 & 7.5 & 8.0 & 8.5 & 9.0 & 9.5 & 10.0\end{array}$

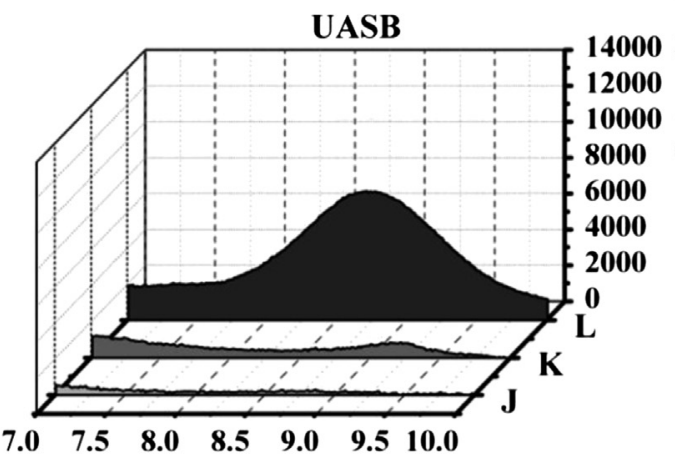

Retention time (min)

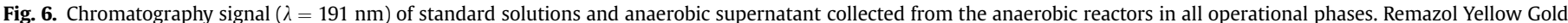

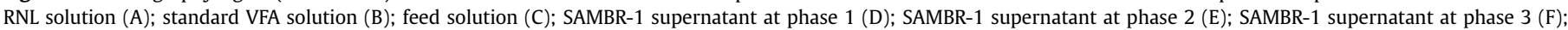

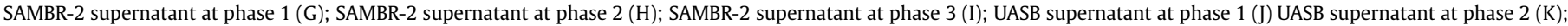
UASB supernatant at phase $3(\mathrm{~L})$.

mechanism for dye removal. Considering the azo dye load (7.2 mg/ h) that entered the SAMBR-1 and assuming removal efficiencies in the range of $89-95 \%$ (Fig. 8), the theoretical time for PAC saturation would be $18-20 \mathrm{~h}$. As during the 80 days of operation no new mass of PAC was added to SAMBR-1, it is clear that the adsorption mechanism cannot solely explain the azo-dye removal in the system. It is noteworthy that the adsorption experiments were carried out with azo dye solutions prepared in distilled water. Since the anaerobic environment contains low molecular weight compounds (e.g. VFA, SMP) that can also be adsorbed by PAC, the Qmax reported here are overestimated, which would imply in a lower amount of azo dye being actually adsorbed in the SAMBR-1. This strengthens the hypothesis that azo dye degradation was the main mechanism of color removal in that system.

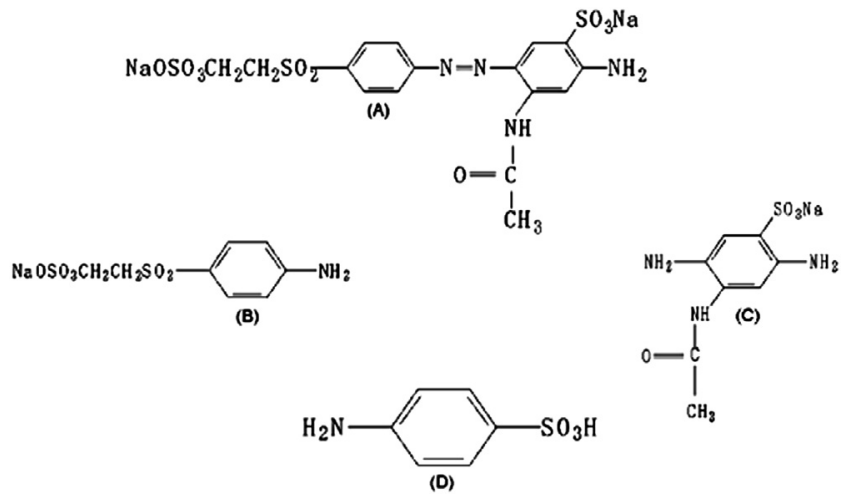

Fig. 7. Chemical structure of Remazol Yellow Gold RNL (A); its possible degradation byproducts (B) e (C); and sulfanilic acid (D).
Another hypothesis for a better color removal performance in SAMBR-1 may be associated to the fact that PAC can also act as a source of immobilized redox mediators, and indeed some authors (Mezohegyi et al., 2010; Pereira et al., 2010; van der Zee et al., 2003) have already shown that the presence of quinone groups onto PAC can accelerate the kinetics of anaerobic degradation of azo dyes. In order to confirm the presence of such groups on the surface of the PAC used inside SAMBR-1, infrared (IR) analyses were carried out as shown in Fig. 9. This figure shows bands at $1669 \mathrm{~cm}^{-1}$ and $1635 \mathrm{~cm}^{-1}$ which are characteristic of $v \mathrm{C}=\mathrm{O}$ stretching in quinones with adjacent carbonyl groups. According to Nakanishi (1962),

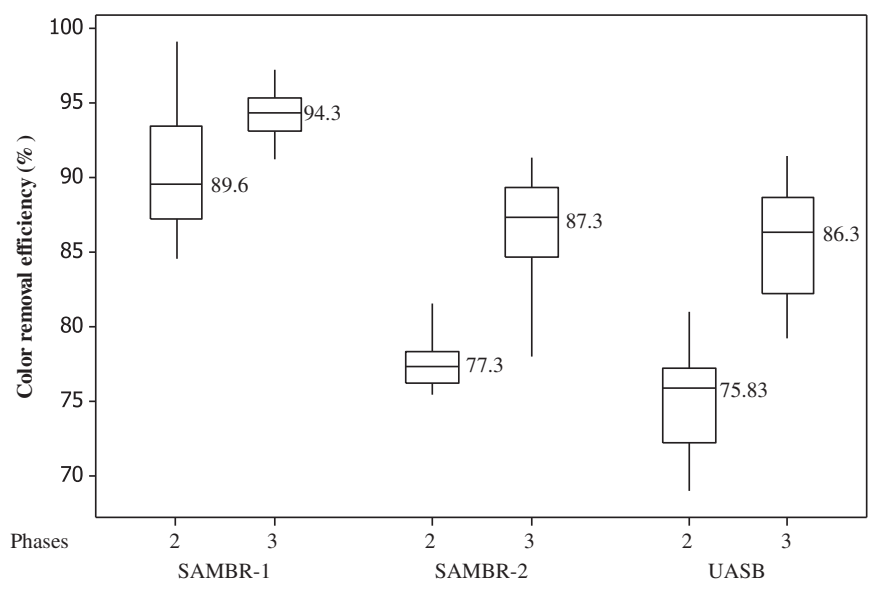

Fig. 8. Color removal efficiency observed in SAMBR-1, SAMBR-2 and UASB in the operational phases the reactors were fed with Remazol Yellow Gold RNL. 


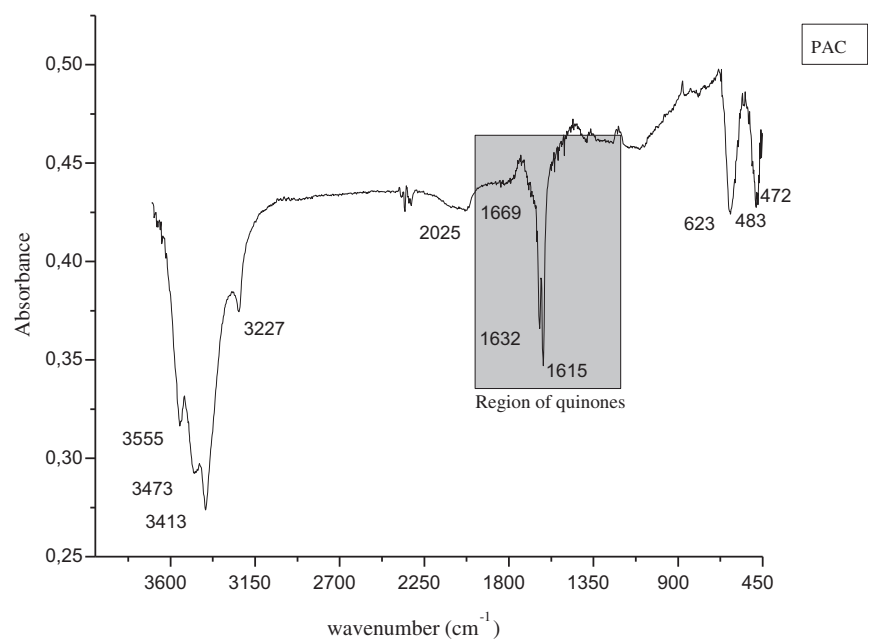

Fig. 9. Infrared spectrum of the PAC used in the SAMBR-1.

quinones with peripheral hydroxyl groups have a strong band at $\sim 1630 \mathrm{~cm}^{-1}$, and a very weak band at $\sim 1675 \mathrm{~cm}^{-1}$. Other authors such as Wen-Tien and Ching-Yuan (1995) also stated that some pquinone show frequency absorbance near $1650 \mathrm{~cm}^{-1}$, while the carbons with $\mathrm{C}=\mathrm{O}$ at the adjacent positions 1 and 2 show the absorbance shifted to $1630 \mathrm{~cm}^{-1}$ and $1600 \mathrm{~cm}^{-1}$. Therefore, as previously reported in the literature, the vibration bands found at $1669 \mathrm{~cm}^{-1}$ and $1632 \mathrm{~cm}^{-1}$ refers to the presence of quinone groups on the surface of PAC used in SAMBR-1.

The association of redox mediators (quinone groups) present onto PAC surface with yeast extract (source of riboflavin) led to the highest color removal efficiency in SAMBR-1 in phase 3 and opens up the opportunity for novel technological processes for wastewater effluents from textile industries.

\section{Conclusion}

- The use of microfiltration membranes inside the anaerobic reactor (SAMBR-1 and SAMBR-2) contributed to the increase of CRT and led to a higher organic matter removal in such reactors;

- The microfiltration membranes showed to be able to remove soluble COD, mainly $\mathrm{COD}_{\mathrm{VFA}}$, probably due to the formation of a biofilm on the membrane surface, thereby contributing to improving the quality of the final effluent;

- The presence of PAC inside the reactor SAMBR-1 improved the stability of the reactor, resulting in higher removal efficiencies of COD, VFA and azo dye. This probably happened due to the ability of PAC in adsorbing byproducts of azo dye degradation (aromatic amines) as well as intermediate organic acids (VFA) formed during anaerobic degradation of organic matter;

- The presence of quinone groups that can act as redox mediators on the surface of the PAC positively contributed with color removal by accelerating the degradation of azo dye Remazol Gold Yellow RNL model. Moreover, the addition of yeast extract enhanced azo dye removal efficiency in all anaerobic reactors tested indicating that such material may in fact be used as a cheap source of the redox mediator riboflavin.

\section{Acknowledgments}

The authors would like to acknowledge the financial support they received from the following Brazilian institutions: CAPES, CNPq and FAPEMIG.

\section{References}

Agbaba, D., Radovic, A., Vladimirov, S., Zivanov-Stakic, D., 1996. Simultaneous TLC determination of co-trimoxazole and impurities of sulfanilamide and sulfanilic acid in pharmaceuticals. J. Chromatogr. Sci. 34, 460-464.

Akram, A., Stuckey, D.C., 2008. Flux and performance improvement in a submerged anaerobic membrane bioreactor (SAMBR) using powdered activated carbon (PAC). Process Biochem. 43, 93-102.

Aquino, S.F., Hu, A.Y., AKram, A., Stuckey, D.C., 2006. Characterization of dissolved compounds in submerged anaerobic membrane bioreactors (SAMBRs). J. Chem. Technol. Biotechnol. 81, 1894-1904.

Aquino, S.F., Chernicharo, C.A.L., 2005. Acúmulo de ácidos graxos voláteis (AGVS) em reatores anaeróbios sob estresse: causa e estratégias de controle. Eng. Sanit Amb 10, 152-161.

Baêta, B.E.L., Ramos, R.L., Lima, D.R.S., Aquino, S.F., 2012a. Use of submerged anaerobic membrane bioreactor (SAMBR) containing powdered activated carbon (PAC) for the treatment of textile effluents. Water Sci. Technol. 65, 1540-1547.

Baêta, B.E.L., Aquino, S.F., Silva, S.Q., Rabelo, C.A., 2012b. Anaerobic degradation of azo dye Drimaren blue HFRL in UASB reactor in the presence of yeast extract a source of carbon and redox mediator. Biodegrad. 23, 199-208.

Cervantes, F.J., Van Der Zee, F.P., Lettinga, G., Field, J.A., 2001. Enhanced decolourisation of acid orange 7 in a continuous UASB reactor with quinones as redox mediators. Water Sci. Technol. 44, 123-128.

Clescerl, L.S., Greenber g, A.E., Eaton, A.D., 2005. Standardmethods for Examination of Water \& Wastewater, twenty-first ed. American Public Health Association.

Correa, C.A.R., Aquino, S.F., Caldas, P.C.P., Silva, S.Q., 2009. Uso de extrato de levedura como fonte de carbono e de mediadores redox para a degradação anaeróbia de corante azo. Eng. Sanit Amb 14, 559-568.

Dereli, R.K., Ersahin, M.E., Ozgun, H., Ozturk, I., Jeison, D., van der Zee, F., Van Lier, J.B., 2012. Potentials of anaerobic membrane bioreactors to overcome treatment limitations induced by industrial wastewaters. Bioresour. Technol. $122,160-170$.

Dos Santos, A.B., Cervantes, F.J., Van Lier, J.B., 2006. Potentials of high-temperature anaerobic treatment and redox mediators for the reductive decolorization of azo dyes from textile wastewaters. Water Sci. Technol. 54, 151-156.

Dos Santos, A.B., Traverse, J., Cervantes, F.J., Van Lier, J.B., 2005. Thermophilic treatment by anaerobic granular sludge as an effective approach to accelerate the electron transfer and improve the reductive decolorization of azo dyes in bioreactors. Water Sci. Technol. 52, 363-369.

Field, J.A., Brady, J., 2003. Riboflavin as a redox mediator accelerating the reduction of the azo dye Mordant yellow 10 by anaerobic granular sludge. Water Sci. Technol. 48, 187-193.

Georgiou, D., Aivasidis, A., 2006. Decoloration of textile wastewater by means of a fluidized-bed loop reactor and immobilized anaerobic bacteria. J. Hazard. Mater. 135, 372-377.

Hu, A.Y., Stuckey, D.C., 2006. Treatment of dilute wastewaters using a novel submerged anaerobic membrane bioreactor. J. Environ. Eng. 132, 190-198.

Hunger, K., Gregory, P., Miederer, P., Berneth, H., Heid, C., Mennicke, W., 2004. Important Chemical Chromophores of Dye Classes, first ed. Wiley-VCH Verlag GmbH \& Co. KGaA.

Kalyuzhnyi, S., Sklyar, V., 2000. Biomineralisation of azo dyes and their breakdown products in anaerobic aerobic hybrid and UASB reactors. Water Sci. Technol. 41, 23-30.

Kumar, P., Prasad, B., Mishra, I.M., Chand, S., 2008. Treatment of composite wastewater of a cotton textile mill by thermolysis and coagulation. J. Hazard. Mater. 151, 770-779.

Liao, B-Qiang, Kraemer, J.T., Bagley, D.M., 2006. Anaerobic membrane bioreactors: applications and research directions, critical reviews. Environ. Sci. Technol. 36, 489-530.

Martinez-Sosa, D., Helmereich, B., Horn, H., 2012. Anaerobic submerged membrane bioreactor (AnSMBR) treating low-strength wastewater under psychrophilic temperature conditions. Process Biochem. 47, 792-798.

Méndez-Paz, D., Omil, F., Lema, J.M., 2005. Anaerobic treatment of azo dye acid orange 7 under fed-batch and continuous conditions. Water Res. 39, 771-778.

Mesquita, P.L., Aquino, S.F., Xavier, A.L.P., Silva, J.C.C., Afonso, R.J.C.F., Silva, S.Q.S., 2010. Soluble microbial products (SMP) characterization in bench-scale aerobic and anaerobic CSTRs under different operational conditions. Braz. J. Chem. Eng. 27, 101-111.

Mesquita, P.L., Leite, G.S., Afonso, R.J.C., Aquino, S.F., 2012. Validation of a liquid chromatography methodology for the 5 simultaneous analyses of seven volatile fatty acids (VFA) 6 intermediates of anaerobic digestion. Eng. Sanit Amb. in press.

Mezohegyi, G., Goncalves, F., Orfao, J.J.M., Fabregat, A., Fortuny, A., Font, J., Bengoa, C., Stuber, F., 2010. Tailored activated carbons as catalysts in biodecolourisation of textile azo dyes. Appl. Catal. B 94, 179-185.

Nakanishi, K., 1962. Infrared Absorption Spectroscopy - Pratical. Holden-Day, Inc., e Nankodo Company Limited, São Franscisco e Tokyo.

Pereira, L., Pereira, R., Pereira, M.F.R., van der Zee, F.P., Cervantes, F.J., Alves, M.M., 2010. Thermal modification of activated carbon surface chemistry improves its capacity as redox mediator for azo dye reduction. J. Hazard. Mater. 183, 931-939.

Pinheiro, H.M., Touraud, E., Thomas, O., 2004. Aromatic amines from azo dye reduction: status review with emphasis on direct UV spectrophotometric detection in textile industry wastewaters. Dyes Pigm. 61, 121-139. 
Rau, J., Knackmuss, H.J., Stolz, A., 2002. Effects of different quinoid redox mediators on the anaerobic reduction of azo dyes by bacteria. Environ. Sci. Technol. 36, 1497-1504.

Santos, V.P., Pereira, M.F.R., Faria, P.C.C., Orfao, J.J.M., 2009. Decolourisation of dye solutions by oxidation with $\mathrm{H}_{2} \mathrm{O}_{2}$ in the presence of modified activated carbons. J. Hazard. Mater. 162, 736-742.

Teixeira, T.P.F., Pereira, S., Aquino, S.F., Dias, A., 2012. Use of calcined layered double hydroxides for decolorization of azo dyes solutions: equilibrium, kinetics and recycling studies. Environ. Eng. Sci. 29, 685-692.
Van Der Zee, F.P., Villaverde, S., 2005. Combined anaerobic-aerobic treatment of azo dyes - a short review of bioreactor studies. Water Res. 39, 1425-1440.

van der Zee, F.P., Bisschops, I.A.E., Lettinga, G., Field, J.A., 2003. Activated carbon as an electron acceptor and redox mediator during the anaerobic biotransformation of azo dyes. Environ. Sci. Technol. 37, 402-408.

Weisburger, J.H., 2002. Comments on the history and importance of aromatic and heterocyclic amines in public health. Muta Res. 506-507, 9-20.

Wen-Tien, Ching-Yuan, 1995. Proc. Natl. Sci. Council, Republic China, Part A: Phys. Sci. Eng., 258-262. (China). 